Meta

Journal des traducteurs

Translators' Journal

\title{
Au pilori
}

\section{La rédaction}

Volume 14, numéro 4, décembre 1969

URI : https://id.erudit.org/iderudit/003929ar

DOI : https://doi.org/10.7202/003929ar

Aller au sommaire du numéro

Éditeur(s)

Les Presses de l'Université de Montréal

ISSN

0026-0452 (imprimé)

1492-1421 (numérique)

Découvrir la revue

Citer cet article

La rédaction (1969). Au pilori. Meta, 14(4), 223-225.

https://doi.org/10.7202/003929ar

Ce document est protégé par la loi sur le droit d'auteur. L'utilisation des services d'Érudit (y compris la reproduction) est assujettie à sa politique d'utilisation que vous pouvez consulter en ligne.

https://apropos.erudit.org/fr/usagers/politique-dutilisation/
Cet article est diffusé et préservé par Érudit.

Érudit est un consortium interuniversitaire sans but lucratif composé de l’Université de Montréal, l'Université Laval et l'Université du Québec à Montréal. Il a pour mission la promotion et la valorisation de la recherche. https://www.erudit.org/fr/ 


\section{AU PILORI}

\section{LA MODE DE PARIS (ONTARIO)}

La maison $\mathrm{M}^{*} \mathrm{M}^{*}$ de Paris (Ontario, thank God!) publie un catalogue de tricots très originaux, du moins par la façon dont ils sont présentés aux clientes de langue française. Tricotons un peu, ma voisine!

"Chère Amie: Saluts aux nouvelles lectrices et un chaleureux «bonjour » aux anciennes amies. Votre dernière copie de notre catalogue présente beaucoup de Nouvelles choses... Créations originales... Elégantes vogues à faire, pour vous... et comme les ardentes tricoteuses sauront constatées, quelques vieux favoris. Vous

1. Henri Bénac, Dictionnaire des synonymes, Paris, Hachette, 1956.

2. Balzac, l'Illustre Gaudissart, cité par Paul Robert, Dictionnaire alphabétique et analogique de la langue française, Paris, Société du Nouveau Littré, 1965, vol. I, p. 843. 
serez surprit de voir comme c'est facile de tricoter, même les vêtements les plus élaborés, avec nos explications facile-à-suivre. N'oubliez pas... Nous offrons un plein Garanti de Chaque Produit!» Quels sont ces «produits»? Pour vous, mesdames, nous recommandons les modèles «L'allure tête aux pieds », «Le casualaire », «Le différend », « aiguisant é bizarre » (très bizarre en effet), ou encore "Bridgitte », "René » ou « Michèlle », à moins que vous ne préfériez «Destiné pour une vogue versatile» ou «Fashionalité ». Mesdemoiselles, nous vous conseillons «Robe impertinente » ou « un cardigan manche raglan qui fera des «choses » pour vous... si facile pour débutantes. $\gg \mathrm{Si}$ vous êtes moins frivoles, choisissez «Doux torsades: Triple panneaux torsades devant et dos, donne beaucoup d'esprit et grande vogue à ce « chasse-bise »col roulé » ou bien « Donne joie: Empiècement Torsades donne un air blasé, si important à la jeunesse. » Quant à vous, messieurs, vous avez le choix entre le modèle «Effronté et bien bâti 》, un "Cardigan encolure-V: ce Style est chez lui avec une blouse, chemise ou plastron encolure roulée ou pullover. Si versatile, action libre. Facile point de jersey » ou, pour les sportifs, « un impétueux modèle diamant», «Allure rugueuse en brillante Northland », "Farouches laineux de l'Ouest», enfin toute une gamme «idéale pour le plaisir et les ébats ».

Tous ces «exclusifs modèles» sont «rapides à tricoter »: «Tricotez un chandail pesanteur légère pour climats modérés, mais assez chaud puor être porter lorsqu'il fait plus froid. Explications écrites pour les six différents styles montrés et beaucoup de laine à tricoter un chandail, aucun style, à la taille désirée. Le patron a aussi une grille unie, pour celle qui désire dessiné leur propre patron... Explications pas à pas en Facile-à-suivre Grille Patron. »

Tournons les pages pour arriver aux « riches et luxueux jetés »: «Vous aimerez la façon que ce charmant jeté apporte du nouveau charme et confort... vous laisse ajouté juste la bonne note de beauté et chaleur à votre foyer. Ce jeté est accentué par des vivides teintes qui chasse la bise. »Préférez-vous les tapis? Vous n'avez que l'embarras du choix: "Paradis de la jungle - Une vraie scène tranquilité jungle qui va dans toute pièce d'après votre goût. Flamant: Faites vos accessoires chambre de bain vous-même dans cet épatant motif flamant. Oeillets: Aussi élégant que de la tapisserie Française, ce tapis ajoutera de la distinction à aucune pièce. Feuilles d'automne: les chaudes nuances des feuilles à l'automne sont en capture glorieuse ici. »

Si cette «suprême collection» vous séduit, il ne vous reste qu'à prendre vos mesures ( Faites rapport à la grille page $51 »$ ), à indiquer vos «prénom, initiales et surnom», et à passer commande ( Vérifier ici ci ceci est votre première commande $\gg$ ).

« Nous apprécions votre intérêt continué dans les produits $M^{*} \mathbf{M}^{*}$. Les dépositaires $M^{*} M^{*}$ ainsi que l'adresse sont énumérés pour votre convénience et guide de choisir celui le plus rapproché de vous. Si parfois ce dépositaire ne peut vous servir vos besoins tricots, s.v.p. ne pas hésiter d'écrire à... » Paris (Ontario!). 
SOYEZ INDULGENT...

Spécialités pour le gourmet

Toutes sortes du fromage

d'autour le Monde.

Confitures, Gelées, et

Conserves pour le connaisseur.

\author{
Bon-bons et Chocolats \\ importés \\ SOYEZ INDULGENT POUR VOTRE BON GOUT - \\ ENTREZ ET PRENEZ VOTRE CHOIX DE NOTRE \\ GROS SÉLECTION DES COMESTIBLES FINS.
}

Nous Sommes Ouvert Jusqu'a 8:30 PM Tous les Soirs.

\title{
LA LANGUE DES DIPLOMATES
}

«It is an indication that there appears to be some room for hoping that eventual solutions can be reached. »

\section{CE QUI SE CONÇOIT BIEN...}

« Where a pay increment is granted to an employee on a day specified pursuant to paragraph (a) of subsection (1), the first pay increment thereafter for that employee shall become due to that employee pursuant to these regulations if the immediately preceding pay increment had been granted to him on the day on which it became due. »

LA RÉDACTION 